\title{
Mathematic and computer modeling of cohesion effect forces on spatial deformation processes of soil massif
}

\author{
Vlasyuk A. P. ${ }^{1}$, Zhukovska N. A. ${ }^{2}$, Zhukovskyy V. V. ${ }^{2}$ \\ ${ }^{1}$ The National University of Ostroh Academy, \\ 2 Seminarska Str., 35800, Ostroh, Ukraine \\ ${ }^{2}$ The National University of Water and Environmental Engineering, \\ 11 Soborna Str., 33000, Rivne, Ukraine
}

(Received 20 February 2020; Revised 18 May 2020; Accepted 20 May 2020)

\begin{abstract}
The article presents the modeling and solving of the deformation processes problem of the soil massif under the forces of cohesion effect. Spatial deformation processes of soil massif are described by the components of displacements, by normal and tangential stresses, and by strains. Also, the corresponding boundary value problem includes the mass and heat transfer equations in a soil massif. The functions of cohesion forces in the soil are considered that have linear, quadratic and logarithmic dependence. The results of the studies are presented in the form of graphs of displacement surfaces as well as in percentage ratios of the corresponding functions. Numerical experiments have shown that on average the forces of linear dependence have the greatest influence on the displacement while the logarithmic dependence provides the least effect.
\end{abstract}

Keywords: mathematical and computer modeling, soil massif, spatial deformation processes, forces of cohesion.

2010 MSC: 65N06, 35C99, 68N99

DOI: $10.23939 / \mathrm{mmc} 2020.01 .196$

\section{Introduction}

The hydrogeological characteristics of the soil massif depend on the influence of various human activity factors: pollution of groundwater with various salts and fertile lands with radioactive substances, temperature fluctuations, dumping of waste products, construction of nuclear power plants and reservoirscoolers near them, etc. At the same time the filtration properties and the stress-strain state (SSS) of soil massifs and bases may change due to the hydrodynamic forces of the filtration flow and the change in the proper weight of the soil. This effect is often the cause of emergencies. Furthermore, maintaining soil fertility is an important task for agricultural production. Mechanical cultivation should provide the optimum stress-strain state of the fertile layer for the purpose of efficient growth of crops. Therefore, an urgent question arises about the study of factors that can influence the deformation processes of soil environments, in particular, taking into account the internal forces of cohesion, which depend not only on the composition of the soil, its moisture and density, but also on the concentration of salt solutions in it.

Mathematical and computer simulation is one of the modern methods of scientific deformation processes prognostication of soil massifs and bases of civil, industrial and hydraulic engineering objects and structures that fall into the zone of influence of various physical and chemical factors.

\section{Analysis of recent research and publications}

The study of deformation processes of soil massifs and bases is reflected in [1,2]. Mathematical modeling and research of the stress-strain state of soil massifs, taking into account mass and heat transfer and the dependences of the filtration coefficient and the Lame's coefficients on the concentration of salt solutions and temperature, as well as the filtration properties of soil massifs are given in [3-6]. The influence of the 
concentration of salt solutions on the forces of cohesion in clay soils was carried out in [7]. Mathematical models in the assessment of water saturated soil massifs' deformations under their drainage have been developed and substantiated in [8]. The mathematical simulation of the landfill settlement was carried out with consideration of geometric, physical and mechanical parameters of a landfill and its ground foundation in [9]. Also, the stress-strain state analysis is specifically concerned with solid objects, because of similarity of fundamental physical lows and that is why there are interesting publications as well. E.g. the novel numerical solution for reducing two-point static problems of distributed extended systems in the field of body and surface forces was presented in [10]. This numerical algorithm may be used for determining power and geometric characteristics of deep water intake of nuclear power plants, assessing the quality of the diverter and determining the stiffness coefficient of the anchor coupling of semi-submersible drilling platform. The finite element method (FEM) used for determination the stress-strain state parameters in the areas of the pipeline part defected by pitting corrosion in [11]. In [12] authors used heterogeneous modeling, boundary element method (BEM), FEM and domain decomposition method (DDM) for numerical analysis of heterogeneous mathematical model of elastic body with thin inclusion. Interesting approach for representing solid materials with discrete lattices and to analysing their behaviour by calculus on discrete manifolds were proposed in [13]. Authors presented mathematical model for elasticity using calculus on discrete manifolds and made the focus on the mathematical derivation of the lattice elements by taking into account the stored energy associated with them. However, the stress-strain state of soil massifs is not considered in these works in consideration of the mass and heat transfer in it and the presence of cohesion forces.

Therefore, the purpose of this article is to study the deformation processes of soil massifs taking into account the influence of mass and heat transfer and forces of cohesion in the three-dimensional case, the construction of the corresponding spatial mathematical model, numerical solution of the corresponding boundary value problem and computer simulation of the obtained results with the subsequent analysis of the obtained results.

\section{Formulation of the problem}

Let us consider the soil massif in the three-dimensional case that occupies the region $\Omega$, taking into account the mass and heat transfer and the forces of cohesion in it (Fig. 1).

The soil massif is considered within the linear theory of elasticity with different elastic parameters (Lame coefficients) $\lambda(c, T), \mu(c, T)$, which depend on the concentration of salt solution and temperature. There are gravity, archimedean and filtration forces influence on the soil .

Let us mark the plane $A B C D$ in Fig. 1 as $\Gamma_{1}$, $A_{1} B_{1} C_{1} D_{1}$ as $\Gamma_{2}, A B A_{1} B_{1}, C D C_{1} D_{1}$ and $B C B_{1} C_{1}$, $A D A_{1} D_{1}$ as $\Gamma_{3}, \Gamma_{4}$ and $\Gamma_{5}, \Gamma_{6}$ respectively. The planes $\Gamma_{1}$ and $\Gamma_{2}$ are heat insulated and impermeable, and $\Gamma_{3}, \Gamma_{4}$, $\Gamma_{5}, \Gamma_{6}$ are drained. On the sides of the soil massif there are water basins with water level $H_{1}$ and $H_{2}$ respectively.

The set values of the piezometric header $\tilde{H}_{1}, \tilde{H}_{2}$, temperatures $\tilde{T}_{1}$ and $\tilde{T}_{2}$ in the water pools $\Gamma_{3}, \Gamma_{5}$ and $\Gamma_{4}, \Gamma_{6}$ respectively, and $\tilde{H}_{1}>\tilde{H}_{2}, \tilde{T}_{1}>\tilde{T}_{2}$. In the left basin, the

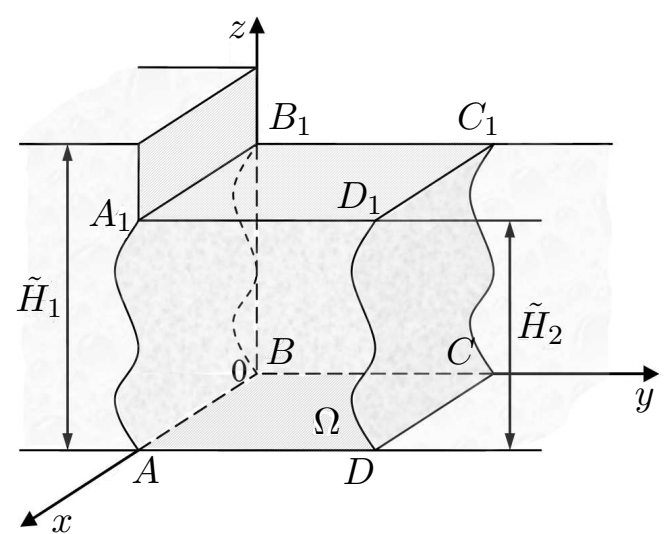

Fig. 1. The scheme of a soil massif in a three-dimensional case. concentration of salts $\tilde{C}_{1}$ is given, and in the right - a condition for the rapid removal of salts. As a result of the pressure differences, the transfer of water-dissolved substances and heat to the filtration stream is carried out. In this case, the processes of filtration of substances dissolved in water and heat are subject to the laws of Darcy, Fick and Fourier.

In this area of the soil massif $\Omega$ it is necessary to calculate the distributions of the displacements $\mathbf{u}(\mathbf{X})=(U(\mathbf{X}), V(\mathbf{X}), W(\mathbf{X}))$, the normal components of the strains $\varepsilon_{x}, \varepsilon_{y}, \varepsilon_{z}$ and the tangential 
components of the strains $\varepsilon_{x y}, \varepsilon_{x z}, \varepsilon_{y z}$, the normal components of the stresses $\sigma_{x}, \sigma_{y}, \sigma_{z}$ and the tangential components of stresses $\tau_{x y}, \tau_{x z}, \tau_{y z}$, the piezometric head $h(\mathbf{X}, t)$, concentration of salt solutions $c(\mathbf{X}, t)$ and temperature $T(\mathbf{X}, t), \mathbf{X} \in \Omega, t>0$ with the presence the forces of cohesion.

\section{Mathematical model}

The mathematical model of the corresponding boundary value problem in the three-dimensional case at the presence of the forces of cohesion and mass and heat transfer in the generally accepted designations has the following form $[1-8,14]$ :

$$
\begin{aligned}
& \mu(c, T) \Delta U+(\lambda(c, T)+\mu(c, T)) \frac{\partial \varepsilon_{\theta}}{\partial x}+\frac{\partial \lambda(c, T)}{\partial x} \varepsilon_{\theta} \\
& +2 \frac{\partial \mu(c, T)}{\partial x} \frac{\partial U}{\partial x}+\frac{\partial \mu(c, T)}{\partial y}\left(\frac{\partial U}{\partial y}+\frac{\partial V}{\partial x}\right)+\frac{\partial \mu(c, T)}{\partial z}\left(\frac{\partial U}{\partial z}+\frac{\partial W}{\partial x}\right) \\
& -\left(\left(3 \frac{\partial \lambda(c, T)}{\partial x}+2 \frac{\partial \mu(c, T)}{\partial x}\right) T+(3 \lambda(c, T)+2 \mu(c, T)) \frac{\partial T}{\partial x}\right) \alpha_{T}+X=0, \\
& \mu(c, T) \Delta V+(\lambda(c, T)+\mu(c, T)) \frac{\partial \varepsilon_{\theta}}{\partial y}+\frac{\partial \lambda(c, T)}{\partial y} \varepsilon_{\theta} \\
& +2 \frac{\partial \mu(c, T)}{\partial y} \frac{\partial V}{\partial y}+\frac{\partial \mu(c, T)}{\partial x}\left(\frac{\partial U}{\partial y}+\frac{\partial V}{\partial x}\right)+\frac{\partial \mu(c, T)}{\partial z}\left(\frac{\partial V}{\partial z}+\frac{\partial W}{\partial y}\right) \\
& -\left(\left(3 \frac{\partial \lambda(c, T)}{\partial y}+2 \frac{\partial \mu(c, T)}{\partial y}\right) T+(3 \lambda(c, T)+2 \mu(c, T)) \frac{\partial T}{\partial y}\right) \alpha_{T}+Y=0, \\
& \mu(c, T) \Delta W+(\lambda(c, T)+\mu(c, T)) \frac{\partial \varepsilon_{\theta}}{\partial z}+\frac{\partial \lambda(c, T)}{\partial z} \varepsilon_{\theta} \\
& +2 \frac{\partial \mu(c, T)}{\partial z} \frac{\partial W}{\partial z}+\frac{\partial \mu(c, T)}{\partial x}\left(\frac{\partial U}{\partial z}+\frac{\partial W}{\partial x}\right)+\frac{\partial \mu(c, T)}{\partial y}\left(\frac{\partial V}{\partial z}+\frac{\partial W}{\partial y}\right) \\
& -\left(\left(3 \frac{\partial \lambda(c, T)}{\partial z}+2 \frac{\partial \mu(c, T)}{\partial z}\right) T+(3 \lambda(c, T)+2 \mu(c, T)) \frac{\partial T}{\partial z}\right) \alpha_{T}+Z=0, \\
& X=\frac{d p_{1}}{d x}+f_{1}(c), \quad Y=\frac{d p_{2}}{d y}+f_{2}(c), \quad Z=\gamma_{z v .}+\frac{d p_{3}}{d z}+f_{3}(c), \\
& \varepsilon_{x}=\frac{\partial U}{\partial x}, \quad \varepsilon_{y}=\frac{\partial V}{\partial y}, \quad \varepsilon_{z}=\frac{\partial W}{\partial z}, \\
& \varepsilon_{x y}=\frac{1}{2}\left(\frac{\partial U}{\partial y}+\frac{\partial V}{\partial x}\right), \quad \varepsilon_{x z}=\frac{1}{2}\left(\frac{\partial U}{\partial z}+\frac{\partial W}{\partial x}\right), \quad \varepsilon_{y z}=\frac{1}{2}\left(\frac{\partial V}{\partial z}+\frac{\partial W}{\partial y}\right), \\
& \sigma_{x}=\lambda(c, T) \varepsilon_{\theta}+2 \mu(c, T) \varepsilon_{x}-(3 \lambda(c, T)+2 \mu(c, T)) \alpha_{T} \bar{T}, \\
& \sigma_{y}=\lambda(c, T) \varepsilon_{\theta}+2 \mu(c, T) \varepsilon_{y}-(3 \lambda(c, T)+2 \mu(c, T)) \alpha_{T} \bar{T}, \\
& \sigma_{z}=\lambda(c, T) \varepsilon_{\theta}+2 \mu(c, T) \varepsilon_{z}-(3 \lambda(c, T)+2 \mu(c, T)) \alpha_{T} \bar{T}, \\
& \tau_{x y}=2 \mu(c, T) \varepsilon_{x y}, \quad \tau_{x z}=2 \mu(c, T) \varepsilon_{x z}, \quad \tau_{y z}=2 \mu(c, T) \varepsilon_{y z},
\end{aligned}
$$

where $\varepsilon_{\theta}=\varepsilon_{x}+\varepsilon_{y}+\varepsilon_{z}, \mathbf{X} \in \Omega$; and the equation of convective diffusion in the presence of mass and heat transfer, convection mass and heat transfer equation, generalized equation of filtration of salt solutions in nonisothermal conditions and the equation of continuity of the process at appropriate boundary conditions on the boundaries of the soil massif for the piezometric head, salt concentration, temperature, displacements and stresses [4]. 
Here: (1) is a system of Lame equations describing SSS for displacements taking into account mass and heat transfer; (2) are the components of mass forces with the cohesion effect present; (3) are the normal and the tangential strains based on the Cauchy ratios; (4) are the normal and the tangential stresses based of the generalized Hooke's law in the inverse form.

The mathematical model (1)-(4) uses the following notation: $\mathbf{X}=(x, y, z)$, the point of the region $\Omega, \mathbf{X} \in \Omega ; \Gamma$, the boundary of the region $\Omega ; t$, time, $t>0 ; \mathbf{u}=(U, V, W)$, the displacements vector, $\mathrm{m} ; X, Y, Z$ are the components of mass force, $H ; \varepsilon_{x}, \varepsilon_{y}, \varepsilon_{z}$ and $\varepsilon_{x y}, \varepsilon_{x z}, \varepsilon_{y z}$, the normal and tangential strains respectively; $\sigma_{x}, \sigma_{y}, \sigma_{z}$ and $\tau_{x y}, \tau_{x z}, \tau_{y z}$, the normal and tangential stresses, $\mathrm{Pa} ; \varepsilon_{\theta}=\varepsilon_{x}+\varepsilon_{y}+\varepsilon_{z} ; p_{1}, p_{2}, p_{3}$, filtration pressure of salt solution, where $p_{1}=\gamma_{p}(h(\mathbf{X}, t)-x)$, $p_{2}=\gamma_{p}(h(\mathbf{X}, t)-y), p_{3}=\gamma_{p}(h(\mathbf{X}, t)-z), \mathrm{Pa} ; c(\mathbf{X}, t)$, concentration of salt solution, $\frac{g}{l} ; T(\mathbf{X}, t)$, temperature, ${ }^{\circ} \mathrm{C} ; h(\mathbf{X}, t)$, piezometric head, $\mathrm{m} ; f_{1}(c), f_{2}(c), f_{3}(c)$ are the functions that express the influence of soil density on its deformation processes due to the forces of cohesion; $\lambda(c, T)$ and $\mu(c, T)$ are the Lame coefficients depending on the concentration of salt solution and temperature, Pa; $\gamma_{z v}$, the proportion of the soil that is in a suspended state, $\frac{\mathrm{Pa}}{\mathrm{m}} ; \alpha_{T}$, the average coefficient of linear thermal expansion in the temperature interval $\left(T_{0}, T\right)[15]$.

\section{Numerical solution of the boundary value problem}

Let us cover the study area $\bar{Q}_{T}=\bar{\Omega} \times\left[0, t_{0}\right]$ with uniform grid

$$
\bar{Q}^{\left(m_{1}, m_{2}, m_{3}, n_{1}\right)}=\left(\left[0 ; m_{1} h_{1}\right] \times\left[0 ; m_{2} h_{2}\right] \times\left[0 ; m_{3} h_{3}\right]\right) \times\left[0 ; n_{1} \tau\right]
$$

with steps $h_{1}, h_{2}, h_{3}$ and $\tau$ according to the variables $x, y, z$ and time $t$, where $m_{1}, m_{2}, m_{3}, n_{1}$ are the numbers of steps for spatial variables and time, respectively.

To approximate the system of equations (1), we use a finite difference method, including the nine-point box template (Fig. 2).

Then the finite-difference analogs of the system of equations (1) have the next form:

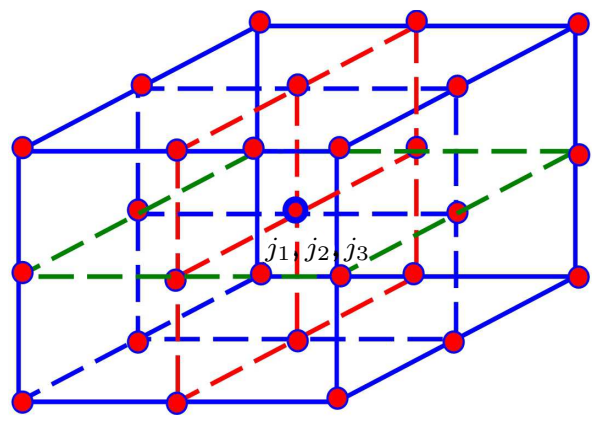

Fig. 2. The nine-point box template.

$$
\begin{aligned}
& \mu_{i, j_{1}, j_{2}, j_{3}} \bar{U}_{i, j_{1}, j_{2}, j_{3}}+\left(\lambda_{i, j_{1}, j_{2}, j_{3}}+\mu_{i, j_{1}, j_{2}, j_{3}}\right) \frac{U_{i, j_{1}+1, j_{2}, j_{3}}-2 U_{i, j_{1}, j_{2}, j_{3}}+U_{i, j_{1}-1, j_{2}, j_{3}}}{h_{1}^{2}} \\
&+\left(\frac{\lambda_{i, j_{1}+1, j_{2}, j_{3}}-\lambda_{i, j_{1}, j_{2}, j_{3}}}{h_{1}}+2 \frac{\mu_{i, j_{1}+1, j_{2}, j_{3}}-\mu_{i, j_{1}, j_{2}, j_{3}}}{h_{1}}\right) \frac{U_{i, j_{1}+1, j_{2}, j_{3}}-U_{i, j_{1}, j_{2}, j_{3}}}{h_{1}} \\
&+\frac{\mu_{i, j_{1}, j_{2}+1, j_{3}}-\mu_{i, j_{1}, j_{2}, j_{3}}}{h_{2}} \frac{U_{i, j_{1}, j_{2}+1, j_{3}}-U_{i, j_{1}, j_{2}, j_{3}}}{h_{2}} \\
&+\frac{\mu_{i, j_{1}, j_{2}, j_{3}+1}-\mu_{i, j_{1}, j_{2}, j_{3}}}{h_{3}} \frac{U_{i, j_{1}, j_{2}, j_{3}+1}-U_{i, j_{1}, j_{2}, j_{3}}}{h_{3}}=f_{i, j_{1}, j_{2}, j_{3}}^{1}\left(V_{i}, W_{i}, T_{i}\right),
\end{aligned}
$$

$$
\begin{gathered}
\mu_{i, j_{1}, j_{2}, j_{3}} \bar{V}_{i, j_{1}, j_{2}, j_{3}}+\left(\lambda_{i, j_{1}, j_{2}, j_{3}}+\mu_{i, j_{1}, j_{2}, j_{3}}\right) \frac{V_{i, j_{1}, j_{2}+1, j_{3}}-2 V_{i, j_{1}, j_{2}, j_{3}}+V_{i, j_{1}, j_{2}-1, j_{3}}}{h_{2}^{2}} \\
+\left(\frac{\lambda_{i, j_{1}, j_{2}+1, j_{3}}-\lambda_{i, j_{1}, j_{2}, j_{3}}}{h_{2}}+2 \frac{\mu_{i, j_{1}, j_{2}+1, j_{3}}-\mu_{i, j_{1}, j_{2}, j_{3}}}{h_{2}}\right) \frac{V_{i, j_{1}, j_{2}+1, j_{3}}-V_{i, j_{1}, j_{2}, j_{3}}}{h_{2}} \\
+\frac{\mu_{i, j_{1}+1, j_{2}, j_{3}}-\mu_{i, j_{1}, j_{2}, j_{3}}}{h_{1}} \frac{V_{i, j_{1}+1, j_{2}, j_{3}}-V_{i, j_{1}, j_{2}, j_{3}}}{h_{1}} \\
+\frac{\mu_{i, j_{1}, j_{2}, j_{3}+1}-\mu_{i, j_{1}, j_{2}, j_{3}}}{h_{3}} \frac{V_{i, j_{1}, j_{2}, j_{3}+1}-V_{i, j_{1}, j_{2}, j_{3}}}{h_{3}}=f_{i, j_{1}, j_{2}, j_{3}}^{2}\left(U_{i}, W_{i}, T_{i}\right),
\end{gathered}
$$




$$
\begin{gathered}
\mu_{i, j_{1}, j_{2}, j_{3}} \bar{W}_{i, j_{1}, j_{2}, j_{3}}+\left(\lambda_{i, j_{1}, j_{2}, j_{3}}+\mu_{i, j_{1}, j_{2}, j_{3}}\right) \frac{W_{i, j_{1}, j_{2}, j_{3}+1}-2 W_{i, j_{1}, j_{2}, j_{3}}+W_{i, j_{1}, j_{2}, j_{3}-1}}{h_{3}^{2}} \\
+\left(\frac{\lambda_{i, j_{1}, j_{2}, j_{3}+1}-\lambda_{i, j_{1}, j_{2}, j_{3}}}{h_{3}}+2 \frac{\mu_{i, j_{1}, j_{2}, j_{3}+1}-\mu_{i, j_{1}, j_{2}, j_{3}}}{h_{3}}\right) \frac{W_{i, j_{1}, j_{2}, j_{3}+1}-W_{i, j_{1}, j_{2}, j_{3}}}{h_{3}} \\
+\frac{\mu_{i, j_{1}+1, j_{2}, j_{3}}-\mu_{i, j_{1}, j_{2}, j_{3}}}{h_{1}} \frac{W_{i, j_{1}+1, j_{2}, j_{3}}-W_{i, j_{1}, j_{2}, j_{3}}}{h_{1}} \\
+\frac{\mu_{i, j_{1}, j_{2}+1, j_{3}}-\mu_{i, j_{1}, j_{2}, j_{3}}}{h_{2}} \frac{W_{i, j_{1}, j_{2}+1, j_{3}}-W_{i, j_{1}, j_{2}, j_{3}}}{h_{2}}=f_{i, j_{1}, j_{2}, j_{3}}^{3}\left(U_{i}, V_{i}, T_{i}\right),
\end{gathered}
$$

where

$$
\begin{aligned}
\bar{U}_{i, j_{1}, j_{2}, j_{3}}= & \frac{U_{i, j_{1}+1, j_{2}, j_{3}}-2 U_{i, j_{1}, j_{2}, j_{3}}+U_{i, j_{1}-1, j_{2}, j_{3}}}{h_{1}^{2}}+\frac{U_{i, j_{1}, j_{2}+1, j_{3}}-2 U_{i, j_{1}, j_{2}, j_{3}}+U_{i, j_{1}, j_{2}-1, j_{3}}}{h_{2}^{2}} \\
& +\frac{U_{i, j_{1}, j_{2}, j_{3}+1}-2 U_{i, j_{1}, j_{2}, j_{3}}+U_{i, j_{1}, j_{2}, j_{3}-1}}{h_{3}^{2}}, \\
\bar{V}_{i, j_{1}, j_{2}, j_{3}}= & \frac{V_{i, j_{1}+1, j_{2}, j_{3}}-2 V_{i, j_{1}, j_{2}, j_{3}}+V_{i, j_{1}-1, j_{2}, j_{3}}}{h_{1}^{2}}+\frac{V_{i, j_{1}, j_{2}+1, j_{3}}-2 V_{i, j_{1}, j_{2}, j_{3}}+V_{i, j_{1}, j_{2}-1, j_{3}}}{h_{2}^{2}} \\
& +\frac{V_{i, j_{1}, j_{2}, j_{3}+1}-2 V_{i, j_{1}, j_{2}, j_{3}}+V_{i, j_{1}, j_{2}, j_{3}-1}}{h_{3}^{2}}, \\
\bar{W}_{i, j_{1}, j_{2}, j_{3}}= & \frac{W_{i, j_{1}+1, j_{2}, j_{3}}-2 W_{i, j_{1}, j_{2}, j_{3}}+W_{i, j_{1}-1, j_{2}, j_{3}}}{h_{1}^{2}}+\frac{W_{i, j_{1}, j_{2}+1, j_{3}}-2 W_{i, j_{1}, j_{2}, j_{3}}+W_{i, j_{1}, j_{2}-1, j_{3}}}{h_{2}^{2}} \\
& +\frac{W_{i, j_{1}, j_{2}, j_{3}+1}-2 W_{i, j_{1}, j_{2}, j_{3}}+W_{i, j_{1}, j_{2}, j_{3}-1}}{h_{3}^{2}},
\end{aligned}
$$

$f_{i, j_{1}, j_{2}, j_{3}}^{1}\left(V_{i}, W_{i}, T_{i}\right), f_{i, j_{1}, j_{2}, j_{3}}^{2}\left(U_{i}, W_{i}, T_{i}\right), f_{i, j_{1}, j_{2}, j_{3}}^{3}\left(U_{i}, V_{i}, T_{i}\right)$ are some known functions; $j_{1}=\overline{1, m_{1}-1}$, $j_{2}=\overline{1, m_{2}-1}, j_{3}=\overline{1, m_{3}-1}, i=\overline{1,2}$.

Here: $\lambda_{i, j_{1}, j_{2}, j_{3}}=\lambda_{i, j_{1}, j_{2}, j_{3}}\left(c_{i, j_{1}, j_{2}, j_{3}}^{(s)}, T_{i, j_{1}, j_{2}, j_{3}}^{(s)}\right), \mu_{i, j_{1}, j_{2}, j_{3}}=\mu_{i, j_{1}, j_{2}, j_{3}}\left(c_{i, j_{1}, j_{2}, j_{3}}^{(s)}, T_{i, j_{1}, j_{2}, j_{3}}^{(s)}\right)$ at $j_{1}=$ $\overline{1, m_{1}-1}, j_{2}=\overline{1, m_{2}-1}, j_{3}=\overline{1, m_{3}^{*}-1}, s=\overline{0, n_{1}}, i=\overline{1,2}$ and $\lambda_{i, j_{1}, j_{2}, j_{3}}=\lambda_{i, j_{1}, j_{2}, j_{3}}\left(T_{i, j_{1}, j_{2}, j_{3}}^{(s)}\right)$, $\mu_{i, j_{1}, j_{2}, j_{3}}=\mu_{i, j_{1}, j_{2}, j_{3}}\left(T_{i, j_{1}, j_{2}, j_{3}}^{(s)}\right)$ at $j_{1}=\overline{1, m_{1}-1}, j_{2}=\overline{1, m_{2}-1}, j_{3}=\overline{m_{3}^{*}, m_{3}-1}, s=\overline{0, n_{1}}, i=\overline{1,2}$.

Finite-difference analogs for mass forces (2) have the form

$$
\begin{aligned}
X_{i, j_{1}, j_{2}, j_{3}} & = \begin{cases}\frac{\left(p_{1}\right)_{j_{1}+1, j_{2}, j_{3}}-\left(p_{1}\right)_{j_{1}-1, j_{2}, j_{3}}}{2 h_{1}}+f_{1}\left(c_{j_{1}, j_{2}, j_{3}}^{(s)}\right), & j_{3}=\overline{1, m_{3}^{*}}, \quad i=1, \\
0, & j_{3}=\overline{m_{3}^{*}+1, m_{3}-1}, \quad i=2,\end{cases} \\
Y_{i, j_{1}, j_{2}, j_{3}} & = \begin{cases}\frac{\left(p_{2}\right)_{j_{1}, j_{2}+1, j_{3}}-\left(p_{2}\right)_{j_{1}, j_{2}-1, j_{3}}}{2 h_{2}}+f_{2}\left(c_{j_{1}, j_{2}, j_{3}}^{(s)}\right), & j_{3}=\overline{1, m_{3}^{*}}, \quad i=1, \\
0, & j_{3}=\overline{m_{3}^{*}+1, m_{3}-1,} \quad i=2,\end{cases} \\
Z_{i, j_{1}, j_{2}, j_{3}} & = \begin{cases}\gamma_{z v .}+\frac{\left(p_{3}\right)_{j_{1}, j_{2}, j_{3}+1}-\left(p_{3}\right)_{j_{1}, j_{2}, j_{3}-1}}{2 h_{3}}+f_{3}\left(c_{j_{1}, j_{2}, j_{3}}^{(s)}\right), & j_{3}=\overline{1, m_{3}^{*}}, \quad i=1, \\
\gamma_{p r .}, & j_{3}=\overline{m_{3}^{*}+1, m_{3}-1}, \quad i=2,\end{cases}
\end{aligned}
$$

where $\left(p_{1}\right)_{j_{1}, j_{2}, j_{3}}=\gamma_{p}\left(h_{j_{1}, j_{2}, j_{3}}^{(s)}-j_{1} h_{1}\right),\left(p_{2}\right)_{j_{1}, j_{2}, j_{3}}=\gamma_{p}\left(h_{j_{1}, j_{2}, j_{3}}^{(s)}-j_{2} h_{2}\right),\left(p_{3}\right)_{j_{1}, j_{2}, j_{3}}=\gamma_{p}\left(h_{j_{1}, j_{2}, j_{3}}^{(s)}-j_{3} h_{3}\right)$, $j_{1}=\overline{1, m_{1}-1}, j_{2}=\overline{1, m_{2}-1}, s=\overline{0, n_{1}}, i=\overline{1,2}$.

The normal and tangential strains (3) are approximated as follows:

$$
\begin{aligned}
& \left(\varepsilon_{x}\right)_{i, j_{1}, j_{2}, j_{3}}=\frac{U_{i, j_{1}+1, j_{2}, j_{3}}-U_{i, j_{1}-1, j_{2}, j_{3}}}{2 h_{1}}, \\
& \left(\varepsilon_{y}\right)_{i, j_{1}, j_{2}, j_{3}}=\frac{U_{i, j_{1}, j_{2}+1, j_{3}}-U_{i, j_{1}, j_{2}-1, j_{3}}}{2 h_{2}},
\end{aligned}
$$




$$
\begin{aligned}
\left(\varepsilon_{z}\right)_{i, j_{1}, j_{2}, j_{3}} & =\frac{U_{i, j_{1}, j_{2}, j_{3}+1}-U_{i, j_{1}, j_{2}, j_{3}-1}}{2 h_{3}}, \\
\left(\varepsilon_{x y}\right)_{i, j_{1}, j_{2}, j_{3}} & =\frac{1}{4}\left(\frac{U_{i, j_{1}, j_{2}+1, j_{3}}-U_{i, j_{1}, j_{2}-1, j_{3}}}{h_{2}}+\frac{V_{i, j_{1}+1, j_{2}, j_{3}}-V_{i, j_{1}-1, j_{2}, j_{3}}}{h_{1}}\right) \\
\left(\varepsilon_{x z}\right)_{i, j_{1}, j_{2}, j_{3}} & =\frac{1}{4}\left(\frac{U_{i, j_{1}, j_{2}, j_{3}+1}-U_{i, j_{1}, j_{2}, j_{3}-1}}{h_{3}}+\frac{W_{i, j_{1}+1, j_{2}, j_{3}}-W_{i, j_{1}-1, j_{2}, j_{3}}}{h_{1}}\right) \\
\left(\varepsilon_{y z}\right)_{i, j_{1}, j_{2}, j_{3}} & =\frac{1}{4}\left(\frac{V_{i, j_{1}, j_{2}, j_{3}+1}-V_{i, j_{1}, j_{2}, j_{3}-1}}{h_{3}}+\frac{W_{i, j_{1}, j_{2}+1, j_{3}}-W_{i, j_{1}, j_{2}-1, j_{3}}}{h_{2}}\right) \\
j_{1} & =\overline{1, m_{1}-1}, j_{2}=\overline{1, m_{2}-1}, j_{3}=\overline{1, m_{3}-1}, i=\overline{1,2} .
\end{aligned}
$$

The finite-difference analogs of normal and tangential stresses (4) have the following form:

$$
\begin{aligned}
& \left(\sigma_{x}\right)_{i, j_{1}, j_{2}, j_{3}}=\lambda_{i, j_{1}, j_{2}, j_{3}}\left(\varepsilon_{\theta}\right)_{i, j_{1}, j_{2}, j_{3}}+2 \mu_{i, j_{1}, j_{2}, j_{3}}\left(\varepsilon_{x}\right)_{i, j_{1}, j_{2}, j_{3}}-\left(3 \lambda_{i, j_{1}, j_{2}, j_{3}}+2 \mu_{i, j_{1}, j_{2}, j_{3}}\right) \alpha_{T}^{(i)} \bar{T}_{i, j_{1}, j_{2}, j_{3}}^{(s)}, \\
& \left(\sigma_{y}\right)_{i, j_{1}, j_{2}, j_{3}}=\lambda_{i, j_{1}, j_{2}, j_{3}}\left(\varepsilon_{\theta}\right)_{i, j_{1}, j_{2}, j_{3}}+2 \mu_{i, j_{1}, j_{2}, j_{3}}\left(\varepsilon_{y}\right)_{i, j_{1}, j_{2}, j_{3}}-\left(3 \lambda_{i, j_{1}, j_{2}, j_{3}}+2 \mu_{i, j_{1}, j_{2}, j_{3}}\right) \alpha_{T}^{(i)} \bar{T}_{i, j_{1}, j_{2}, j_{3}}^{(s)}, \\
& \left(\sigma_{z}\right)_{i, j_{1}, j_{2}, j_{3}}=\lambda_{i, j_{1}, j_{2}, j_{3}}\left(\varepsilon_{\theta}\right)_{i, j_{1}, j_{2}, j_{3}}+2 \mu_{i, j_{1}, j_{2}, j_{3}}\left(\varepsilon_{z}\right)_{i, j_{1}, j_{2}, j_{3}}-\left(3 \lambda_{i, j_{1}, j_{2}, j_{3}}+2 \mu_{i, j_{1}, j_{2}, j_{3}}\right) \alpha_{T}^{(i)} \bar{T}_{i, j_{1}, j_{2}, j_{3}}^{(s)}, \\
& \left(\tau_{x y}\right)_{i, j_{1}, j_{2}, j_{3}}=2 \mu_{i, j_{1}, j_{2}, j_{3}}\left(\varepsilon_{x y}\right)_{i, j_{1}, j_{2}, j_{3}}, \\
& \left(\tau_{x z}\right)_{i, j_{1}, j_{2}, j_{3}}=2 \mu_{i, j_{1}, j_{2}, j_{3}}\left(\varepsilon_{x z}\right)_{i, j_{1}, j_{2}, j_{3}}, \\
& \left(\tau_{y z}\right)_{i, j_{1}, j_{2}, j_{3}}=2 \mu_{i, j_{1}, j_{2}, j_{3}}\left(\varepsilon_{y z}\right)_{i, j_{1}, j_{2}, j_{3}},
\end{aligned}
$$

where $\left(\varepsilon_{\theta}\right)_{i, j_{1}, j_{2}, j_{3}}=\left(\varepsilon_{x}\right)_{i, j_{1}, j_{2}, j_{3}}+\left(\varepsilon_{y}\right)_{i, j_{1}, j_{2}, j_{3}}+\left(\varepsilon_{z}\right)_{i, j_{1}, j_{2}, j_{3}}, \bar{T}_{i, j_{1}, j_{2}, j_{3}}^{(s)}=, j_{1}=\overline{1, m_{1}-1}, j_{2}=\overline{1, m_{2}-1}$, $j_{3}=\overline{1, m_{3}-1}, i=\overline{1,2}, s=\overline{0, n_{1}}$.

An approximation of the boundary conditions for displacements is given in [6] as well as approximations of concentration and temperature mode in [3]. To find the displacement values $U(\mathbf{X}), V(\mathbf{X})$ and $W(\mathbf{X})$ and the piezometric head $h(\mathbf{X}, t)$, the Gauss-Seidel iteration method was used and described in [6]. To find the concentration of salt solution $c(\mathbf{X}, t)$ and temperature $T(\mathbf{X}, t)$, a sweep method [16] was used.

\section{Experiments and their analysis}

For numerical solving and computer simulation of the corresponding boundary value problem, a software package for the capabilities of the Microsoft Visual Studio 2017 framework for Windows Desktop in the $\mathrm{C} \#$ programming language was created, in which graphs and table data show the displacement fields distributions, the component of normal and tangential strains and stresses, as well as pressure, concentration of salts and temperature in the studied area, taking into account and without taking into account the influence of mass and heat transfer and the presence of the forces of cohesion.

As an example, the spatial stress-strain state in a soil massif in the region $\Omega=\{\mathbf{X}=(x, y, z): 0 \leqslant$ $\left.x \leqslant l_{1}, 0 \leqslant y \leqslant l_{2}, 0 \leqslant z \leqslant l_{3}\right\}$, which has the shape of a rectangular parallelepiped of $l_{1}=10 \mathrm{~m}$ length, $l_{2}=10 \mathrm{~m}$ thickness and $l_{3}=10 \mathrm{~m}$ height with $\alpha_{T}=1 \cdot 10^{-6} \frac{1}{\mathrm{grad}}, \gamma_{z v}=1.3 \cdot 10^{4} \frac{\mathrm{Pa}}{\mathrm{m}}, \gamma_{p}=1 \cdot 10^{4} \frac{\mathrm{Pa}}{\mathrm{m}}$ and with the following functions $f_{1}(c)=f_{2}(c)=f_{3}(c)=f(c)$, is considered:

a) $f(c)=a c+b, a=$ const, $b=$ const (linear function);

b) $f(c)=\sqrt{a c+b}, a=$ const, $b=$ const (quadratic function);

c) $f(c)=a \cdot \ln (c b), a=$ const, $b=$ const (logarithmic function).

The dependences of the Lame coefficients and the filtration coefficient on the concentration of salt solutions is taken from [17].

A series of numerical experiments was conducted, the results of which are presented in the form of graphs at $t=1080$ days. 
Fig. 3 shows the displacements graphs $U(\mathbf{X}), V(\mathbf{X})$ and $W(\mathbf{X})$ in the section of the plane $x O y$ at $z=5 \mathrm{~m}$, taking into account the mass and heat transfer and the presence of cohesion forces at $a=1$ and $b=1$.
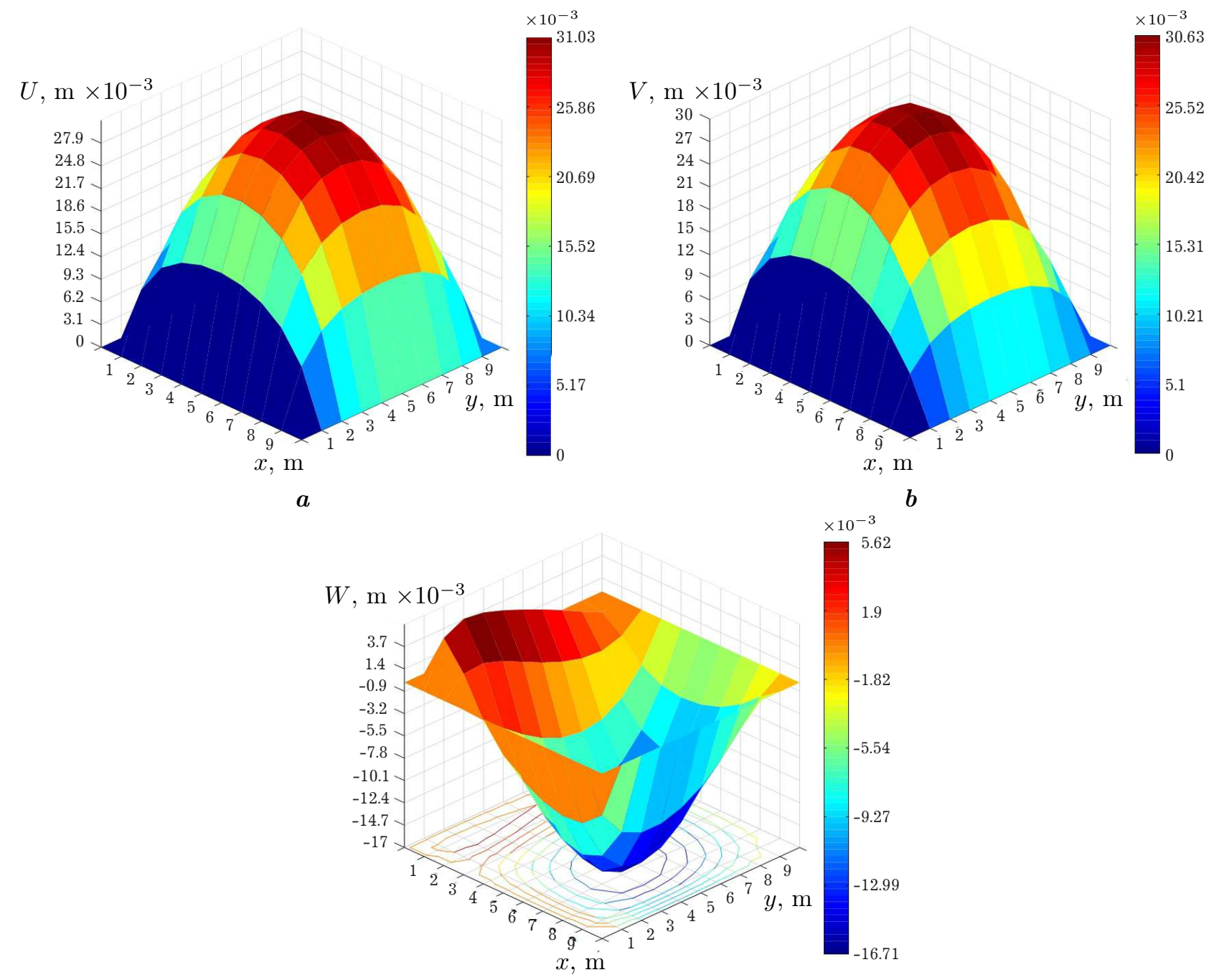

$c$

Fig. 3. Distributions of displacements $U(\mathbf{X})(\boldsymbol{a}), V(\mathbf{X})(\boldsymbol{b})$ and $W(\mathbf{X})(\boldsymbol{c})$ with logarithmic dependence of cohesion forces function.

Similar graphs are obtained for components of the normal and tangential strains and stresses. Based on the results of numerical experiments the following conclusions were obtained:

1. The displacements along the $O x$ axis $(U(\mathbf{X}))$, taking into account the linear function of the forces of cohesion, decreased by an average of $1.37 \%$, quadratic function by $0.09 \%$ and logarithmic function by $0.03 \%$ compared with the displacements along the $O x$ axis without taking into account the forces of cohesion [5].

2. The displacements along the $O y$ axis $(V(\mathbf{X}))$, taking into account the linear function of the forces of cohesion on average decreased by $1.37 \%$, quadratic function by $0.09 \%$ and logarithmic function by $0.03 \%$ compared with displacements along the $O y$ axis without taking into account the forces of cohesion.

3. The displacements along the $O z$ axis $(W(\mathbf{X}))$, taking into account the linear function of the forces of cohesion, on average decreased by $3.61 \%$, the quadratic function by $0.24 \%$ and logarithmic 
function by $0.09 \%$ compared with the displacements along the $O z$ axis without taking into account the forces of cohesion.

4. The normal strains along the $O x$ axis $\left(\varepsilon_{x}\right)$, taking into account the linear function of the forces of cohesion, on average decreased by $1.15 \%$, the quadratic function by $0.03 \%$, the logarithmic function by $0.001 \%$ compared with the normal strains along the $O x$ axis without taking into account the forces of cohesion.

5. The normal strains along the $O y$ axis $\left(\varepsilon_{y}\right)$, taking into account the linear function of the forces of cohesion, on average decreased by $39.79 \%$, the quadratic function by $1.17 \%$, the logarithmic function by $0.07 \%$ compared to the normal strains along the $O y$ axis without taking into account the forces of cohesion.

6. The normal strains along the $O z$ axis $\left(\varepsilon_{z}\right)$, taking into account the linear function of the forces of cohesion, on average decreased by $2.12 \%$, the quadratic function by $0.08 \%$, and the logarithmic function by $0.01 \%$, as compared to the normal strains along the $O z$ axis without taking into account the forces of cohesion.

7. The normal stresses on the $O x$ axis $\left(\sigma_{x}\right)$, taking into account the linear function of the forces of cohesion, on average decreased by $0.33 \%$, the quadratic function by $0.13 \%$, logarithmic function by $0.07 \%$ compared with the normal stresses on the $O x$ axis without taking into account the forces of cohesion.

8. The normal stresses on the $O y$ axis $\left(\sigma_{y}\right)$, taking into account the linear function of the forces of cohesion, on average decreased by $0.48 \%$, the quadratic function by $0.06 \%$, logarithmic function by $0.04 \%$ compared with the normal stresses on the $O y$ axis without taking into account the forces of cohesion.

9. The normal stresses on the $O z$ axis $\left(\sigma_{z}\right)$, taking into account the linear function of the forces of cohesion, on average decrease by $0.21 \%$, the quadratic function by $0.15 \%$, and the logarithmic function by $0.09 \%$ compared to the normal stresses on the $O z$ axis without taking into account the forces of cohesion.

10. The tangential strains to the $x O y$ plane, taking into account the linear function of the forces of cohesion, on average decreased by $55.04 \%$, the quadratic function by $1.61 \%$ and the logarithmic function by $0.1 \%$ compared to the tangential strains to the $x O y$ plane without taking into account the forces of cohesion.

11. The tangential strains to the $x O z$ plane, taking into account the linear function of the forces of cohesion, on average decreased by $4.84 \%$, the quadratic function by $0.14 \%$, the logarithmic function by $0.01 \%$ in comparison with the tangential strains to the $x O z$ plane without taking into account the forces of cohesion.

12. The tangential strains to the $y O z$ plane, taking into account the linear function of the forces of cohesion, on average decreased by $0.92 \%$, the quadratic function by $0.03 \%$, the logarithmic function by $0.001 \%$ in comparison with the tangential strains to the $y O z$ plane without taking into account the forces of cohesion.

13. The tangential stresses to the $x O y$ plane, taking into account the linear function of the forces of cohesion, on average decreased by $0.65 \%$, the quadratic function by $0.03 \%$, and the logarithmic function by $0.03 \%$ compared with the tangential stresses to the $x O y$ plane without taking into account the forces of cohesion.

14. The tangential stresses to the $x O z$ plane, taking into account the linear function of the forces of cohesion, on average decreased by $0.89 \%$, the quadratic function by $0.04 \%$, and the logarithmic function by $0.04 \%$ compared with the tangential stresses to the $x O z$ plane without taking into account the forces of cohesion.

15. The tangential stresses to the $y O z$ plane, taking into account the linear function of the forces of cohesion, on average decreased by $0.26 \%$, the quadratic function by $0.01 \%$, the logarithmic function by $0.01 \%$ in comparison with the tangential stresses to the $y O z$ plane without taking into account the forces of cohesion. 
Thus, taking into account the cohesion forces in the soil massif considered changes the distributions of the displacements, the components of normal and tangential strains and stresses. In particular, the greatest effect occurred with the linear function of the cohesion forces dependence, and the smallest with the logarithmic function.

\section{Conclusion}

The article formulates the problem of mathematical and computer simulation of the spatial stressstrain state of the soil massif, taking into account the influence of mass and heat transfer and the presence of cohesion forces. Numerical solution of the corresponding boundary value problem is found. The software package of the Microsoft Visual Studio 2017 Framework for Windows Desktop in the $\mathrm{C} \#$ programming language has been created for computer simulation, and the soil massif, which has the shape of a rectangular parallelepiped, is considered. The results of computer simulation and numerical experiments are obtained. They demonstrate the cohesion forces effect on the overall spatial deformation processes in the soil massif in non-isothermal conditions.

[1] Sergienko I. V., Skopetskii V.V., Deineka V. S. Mathematical Simulation and Investigation of Processes in Inhomogeneous Media. Naukova Dumka, Kiev (1991), (in Ukarainian).

[2] Hetnarski R. B. Encyclopedia of thermal stresses. Springer Reference, Dordrecht (2014).

[3] Vlasyuka A. P., Zhukovskaya N. A. Mathematical Simulation of the Stressed-Strained State of the Foundation of Earth Dams with an Open Surface Under the Influence of Heat and Mass Transfer in the TwoDimensional Case. Journal of Engineering Physics and Thermophysics. 88 (2), 329-341 (2015).

[4] Vlasyuk A. P., Zhukovska N. A., Zhukovskyy V.V., Klos-Witkowska A., Pazdriy I., Iatsykovska U. Mathematical modelling of three-dimensional problem of soil mass stressed-strained state considering mass and heat transfer: 2017 9th IEEE International Conference on Intelligent Data Acquisition and Advanced Computing Systems: Technology and Applications (IDAACS). Vol. 1, 265-269 (2017).

[5] Vlasyuk A. P., Borowik B., Zhukovska N. A., Zhukovskyy V. V., Karpinskyi V. Computer modelling of heat and mass transfer effect on the three-dimensional stressed-strained state of soil massif. 18th International Multidisciplinary Scientific Geoconference SGEM 2018. Vol. 18, No. 1.2, 153-160 (2018).

[6] Vlasyuk A., Zhukovska N., Zhukovskyy V., Hesham R. Mathematical Modelling of Spatial Deformation Process of Soil Massif with Free Surface. Advances in intelligent systems and computing IV. Vol. 1080, 107-120 (2020).

[7] Kuzlo M. T. Investigation of the effect of the concentration of saline solutions on clutch forces in clay soils. Hydrotechnical construction. 5, 51-53 (2013).

[8] Kuzlo M. T., Moshynskyi V.S., Martyniuk P. M. Mathematical modelling of soil Massif's deformations under its drainage. International Journal of Apllied Mathematics. 31 (6), 751-762 (2019).

[9] Remez N., Osipova T., Kraychuk O., Kraychuk S. Simulation of the solid waste landfill settlement taking into account underlying soil. Eastern-European Journal of Enterprise Technologies. 3 (10), 12-17 (2016).

[10] Kaliukh I., Trofymchuk O., Lebid O. Numerical Solution of Two-Point Static Problems for Distributed Extended Systems by Means of the Nelder-Mead Method. Cybernetics and Systems Analysis. 55 (4), 616-624 (2019).

[11] Vodka O. Computation tool for assessing the probability characteristics of the stress state of the pipeline part defected by pitting corrosion. Advances in Engineering Software. 90, 159-168 (2015).

[12] Dyyak I. I., Rubino B., Savula Y. H., Styahar A. O. Numerical analysis of heterogeneous mathematical model of elastic body with thin inclusion by combined BEM and FEM. Mathematical Modeling and Computing. 6 (2), 239-250 (2019).

[13] Dassios I., O'Keeffe G., Jivkov A. P. A mathematical model for elasticity using calculus on discrete manifolds. Mathematical Methods in the Applied Sciences. 41 (18), 9057-9070 (2018).

[14] Safonyk A., Martynov S., Kunytskyi S., Pinchuk O. Mathematical modelling of regeneration the filtering media bed of granular filters. Advances in Modelling and Analysis. 73 (2), 72-78 (2018).

Mathematical Modeling and Computing, Vol. 7, No. 1, pp. 196-205 (2020) 
[15] Karnaukhov V. G. On A. D. Kovalenko's Research Works on the Thermomechanics of Coupled Fields in Materials and Structural Members and Its Further Development. International Applied Mechanics. 41 (9), 967-975 (2005).

[16] Samarskii A. A. The theory of difference schemes. Vol. 240 of Pure and applied mathematics. Marcel Dekker, New York (2001).

[17] Vlasyuk A. P., Kuzlo M. T. Experimental investigations of some of the parameters of filtration of salt solutions in sandy soils. Melioration and Water Handling Facilities: Interdepartmental Thematic Scientific Collection. 43-46 (2000), (in Ukrainian).

\title{
Математичне і комп'ютерне моделювання впливу сил зв'язності на просторові деформаційні процеси грунтових масивів
}

\author{
Власюк А. П. ${ }^{1}$, Жуковська Н. А. ${ }^{2}$, Жуковський В. В. ${ }^{2}$ \\ ${ }^{1}$ Національний університет «Острозька академія» \\ вул. Семінарсъка, 2, 35800, Острог, Украӥна \\ ${ }^{2}$ Національний університет водного господарства та природокористування \\ вул. Соборна, 11, 35000, Рівне, Україна
}

Стаття присвячена моделюванню та розв'язанню задачі впливу сил зв'язності на деформаційні процеси грунтового масиву. Просторові деформаційні процеси грунтового масиву описуються компонентами зміщень, нормальних і дотичних деформацій та напружень. Також поставлена крайова задача включає рівняння тепло- та масоперенесення в грунтовому масиві. Розглянуто функції сил зв'язності в грунтовому масиві, що мають лінійний, квадратичний та логарифмічний вигляди. Наведено результати досліджень у вигляді графіків поверхонь зміщень та процентних співвідношень шуканих функцій. Як показали проведені чисельні експерименти, в середньому найбільший вплив на зміщення мають сили зв'язності лінійного вигляду, а найменший - логарифічного.

Ключові слова: математичне $і$ комп'ютерне моделювання, грунтовий масив, деформачійні прочеси, сили зв'язності. 